\title{
Analysis of rainfall trend and variability in Ebonyi state, South Eastern Nigeria
}

\author{
Bridget E. Diagi \\ Department of Geography and Environmental Management, University of Port Harcourt Port Harcourt, Nigeria
}

Corresponding Author Email: edeoli@yahoo.com

https://doi.org/10.18280/eesrj.050301

Received: 18 July 2018

Accepted: 22 August 2018

\section{Keywords:}

rainfall, trend, variability, pattern, agriculture

\begin{abstract}
Rainfall pattern, trend and variability, are major indicators used in evaluating any investigation that relate to agriculture particularly because of the crucial role it plays in agricultural productivity. The purpose of this research is basically to examine the extent of variation in rainfall pattern of the study area. This is necessary because the study area is majorly an agrarian community where rainfall agriculture is mainly practiced. Rainfall totals for every month covering a period of 31 years were collected from the Nigeria meteorological agency of Nigeria and analysed for variation, fluctuation using mean, moving average, standard deviation, coefficient of variation and linear regression while Kruskal wallis $\mathrm{H}$ test was used in testing the hypothesis. Result indicated that there have been statistically significant increases in rainfall totals in the study area. Analysis indicates that rainfall possesses a positive trend and as such the area is getting wetter by $8.9318 \mathrm{~mm}$ per annual. In conclusion, agriculture can be improved upon towards creating more jobs for the youths in order to reduce unemployment, achieve food security and ultimately enhance agricultural sustainability. The implication of this increasing rainfall trend for farmers as well as the government is the opportunity to increase crop production and animal rearing since more rainfall can be gathered.
\end{abstract}

\section{INTRODUCTION}

Weather and climate are significant phenomena that affect the environment and activities on the earth surface in diverse way particularly agriculture. Agriculture being one of the most weather-dependent of all human activities is highly vulnerable to climate change [1]. One of the most important climatic elements that determine agricultural productivity in Nigeria and particularly in South-eastern Nigeria is rainfall; this is because agricultural activity in this zone is highly sensitive to rainfall pattern as rain-fed agriculture is majorly practiced [2]; [3-4]. The changes in rainfall pattern as well as the duration are important factors to consider in the areas of agriculture, forest, coastal ecosystem, as well as other aspect of the environment that makes life meaningful to man. Researches have revealed that rainfall is changing on both global and regional level as a result of global warming [5-6]. Although the present warming has been greatly attributed to man activities as a fall out of industrial revolution, yet, it has not been uniformed across the planet, so also are its manifestation, impact and consequences. As a response to the warming in temperature, rainfall has trended downwards in some places and risen in other areas and sea level has risen between 1 to $3 \mathrm{~mm}$ per year [7]. This change in rainfall seems to be having a great influence on the environment particularly the agricultural sector. Researches have shown that Nigeria is already experiencing some effects of these changes in different ecological setting which can be linked to changes in climate [8-12]. These changes in climate could be positive or negative. Instances of this negative impact include incidences of droughts which are now more frequent in some part of the world and in some cases takes a longer time. For examples countries like Rwanda, Kenya, Ethiopia, South Sudan and Somalia experienced some of the worst droughts in decades recently. According to [13], more than 70 million people are facing hunger around the world and one of the primary causes of this hunger has been attributed to drought which is a direct consequence of declining rainfall. In the same vein, four countries, Yemen, Somalia, South Sudan and Nigeria (Northern part) now faces drought. This is because as the planet warms, rainfall patterns tend to shift thereby resulting in extreme events such as droughts, famine, flood, and forest fire which are becoming more frequent and pronounce [14]. An extension of these extreme events could be low agricultural production which will lead to famine and food insecurity. In Ebonyi State, crops and animals derived their water resources largely from rainfall sources. Rainfall is regarded as a major determinant of the crop type to be grown in the State and also the period of cultivation of such crops and the farming systems that is practiced in the area. Rainfall is also regarded as one of the most important climatic variable over West Africa, as it is still the major source of moisture for agricultural activities over this region [15]. Therefore, the trend, variability of rainfall and the pattern of how high or low precipitation occurs in terms of rainfall are very important for agricultural sustainability as well as the economy of the State in general. As a declining and/or rising trend in rainfall trend may be quite informative for the various sectors of the human and natural systems of the State [8]. This research is particularly significant because of the current move by government at all levels to encourage agriculture in Nigeria in order to diversify the economy, ensure adequate food for the populace and generate additional income to support the low revenue from oil. To achieve this, vital information is required for the design 
of water supply and supplemental irrigation system to support agricultural sustainability should the need arise. Therefore, this paper examines the trend and variability of rainfall in Ebonyi State, with the view to providing vital information for planning and policy formulation towards agricultural sustainability for the well- being of the people. This is because Ebonyi State's agricultural productivity is one of the highest in Nigeria.

Research hypothesis:

H0: There is no statistically significant increase in rainfall over the period 1984-2015 in the study area.

\section{DESCRIPTION OF AREA}

The study is located in Ebonyi State depicted in Fig. 1, which is one of the States in South-eastern Nigeria. Ebonyi State lies approximately within latitudes $5^{\circ} 40^{\prime}$ and $6^{\circ} 45^{\prime}$ North of the Equator and longitudes $7^{\circ} 30^{\prime}$ and $8^{\circ} 30^{\prime}$ East of the Greenwich meridian. The prevailing climatic condition in the area is characterized primarily by two regimes which are the rainy and the dry seasons. The rainy season is usually from April to October; while the dry season starts from October through to February. The area can be described as having a bimodal rainfall pattern [16]. The wet season has its first peak in July and the second occurs in September, the area records annual rainfall of between $1613.8 \mathrm{~mm}$ to $2136.27 \mathrm{~mm}$ [17], the dry season starts in November, when the dry continental North-eastern wind blows from the Mediterranean Sea across the Sahara desert and Samarian desert and down to the southern part of Nigeria. About $60-70 \%$ of the dwellers of southeast zone are found to engage in agriculture mainly crop farming [18]. Agriculture is a very significant sector of the economy for the zone and the sources of raw materials used in the processing industries which serve as another area of employment and income generation for the people.

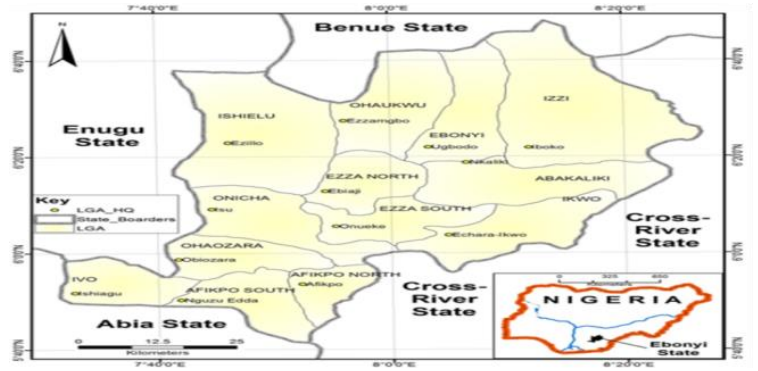

Figure 1. The study area: Ebonyi state, south- eastern Nigeria

\section{MATERIALS AND METHODS}

\subsection{Data Used}

Monthly rainfall data covering 31 years period from 1984 to 2015 for the study area were obtained from the Nigerian Meteorological Agency (NIMET) Oshodi, Lagos.

\subsection{Data analysis}

Data analysis was carried out from the Rainfall data obtained and analyzed for trend and fluctuation using Mean, moving averages, Standard deviation, coefficient of variation and linear regression. Hypothesis was tested using KruskalWallis $\mathrm{H}$ test.

Their expressions are as follows:

\subsubsection{Mean}

The mean statistic is used in the study to determine the differences in the decadal means of the elements as a way of showing decadal variation between 1984 and 2015 .

$x=\sum_{\frac{i=1}{n}}^{n}-x i$

where $\mathrm{i}$ runs from 1 to $\mathrm{n}$; $\mathrm{x}$, the rainfall values, and $\mathrm{n}$, the number of years.

\subsubsection{Moving average or running mean}

Moving average is a smoothing method that is needed to check out some up and down i.e. in finding trend that might exit in data as trends tend to be obscured by the random errors. The simplest way of smoothing a time series data is to use a moving average. An average value is computed by using only a specified set of values. In this study, a 5-year moving average is used.

The 5- years moving average is written as:

$\frac{y_{1}+y_{2}+y_{3}+y_{4}+y_{5}}{n}$

where $\mathrm{n}$ is 5 years order and $\mathrm{y}$ the variable in this case rainfall.

\subsubsection{Standard deviation}

Standard deviation is one of the simplest ways of measuring climate variability by using the standard deviation estimator in measuring dispersion. It is used in this study to show the absolute variability in rainfall from 1984 to 2015. Sample standard deviation $\mathrm{Sx}$ is given as

$s x=\sqrt{\sum \frac{(x i-\bar{x})^{2}}{n-1}} \ldots$

where $S x=$ the estimator of the standard deviation $\sigma x$ of a climate variable $\mathrm{X}$

The closer the value of standard deviation is to zero for any dataset, the smaller is the dispersion. This means that the data values are closer to the mean value of the dataset and that the data is more reliable for analysis [19].

\subsubsection{Coefficient of variation}

It is not easy to interpret the standard deviation as a measure of dispersion on its own. This is because a small value for standard deviation shows that the dispersion of the dataset is low. Nevertheless, the magnitude of these values depends on what is being analysed. Therefore, a method to overcome this difficulty of interpreting the standard deviation is to take into account the value of the mean of the data and employ the use of coefficient of variation. It is used in this study to show the relative variability of rainfall over time. The coefficient of variation, $V x$, is a relative measure of variability and is defined as follows [20]:

$V x \frac{S x}{\bar{x}}$ 


\subsubsection{Kruskal-Wallis H test}

The Kruskal-Wallis $\mathrm{H}$ test is a rank-based nonparametric test which can be used to determine if there are statistically significant differences between two or more groups of an independent variable on a continuous or ordinal dependent variable. It is considered the nonparametric alternative to the one-way ANOVA, and an extension of the Mann-Whitney U test to allow the comparison of more than two independent groups. It is used to test the Hypothesis stated. The Kruskal test statistics is as follows:

$\mathrm{H}=\frac{12}{n(n+1)} \sum_{J=1}^{c}=1 \frac{R i^{2}}{n i}-3(n+1)$

where

$\mathrm{N}=$ sum of sample sizes for all samples,

$\mathrm{C}=$ number of samples

$\mathrm{T}_{\mathrm{j}}$ = sum of ranks in the jth sample,

$\mathrm{n}_{\mathrm{j}}=$ Size of the $\mathrm{jth}$ sample

\subsubsection{Linear regression}

The least squares regression is used in the study to model the trends in rainfall data over the 31 years period. The result helps to determine the overall average rates of change in trends of annual rainfall totals in the study area.

The equation for least square regression is

$\mathrm{Y}=\mathrm{a}+\mathrm{b} x$

where

$\mathrm{b}=\frac{n \sum x y-\left(\sum x\right)\left(\sum y\right)}{n \sum x^{2}-\left(\sum x\right)^{2}}$

And

$\mathrm{a}=\frac{\sum y}{n}-\frac{b \sum x}{n}=\bar{y}-b \bar{x}$

$\mathrm{a}$ is the intercept; $\mathrm{b}$ the regression coefficient or slope;

$\mathrm{y}=$ the rainfall values (dependent variable);

$\mathrm{x}=$ the time in years ; (independent variable)

$\overline{\mathrm{x}}=$ the mean time; and

$\bar{y}=$ the mean rainfall value.

\section{RESULTS AND DISCUSSION}

\subsection{Rainfall trend, pattern and variability}

After applying a 5-year moving averages to filter out the irregular fluctuations between successive rainfall observations, annual rainfall trend lines were drawn leaving only a few peaks and depression (Figure 2). Thereafter, the linear regression was applied to show the trend, intercepts, slopes and regression lines. The result generated is shown in table one and as graphs in figure 2. Results showed that rainfall possess an upward trend which means that the study area is getting wetter by $8.937 \mathrm{~mm}$ annually. The annual rate of increase in rainfall totals $(8.937 \mathrm{~mm})$ has implication for other component of weather and climate this is because this increase in annual rainfall totals will make the area even wetter. This would bring about increase in evapotranspiration if wet surfaces exist and by extension other component of the ecosystem such as vegetation, agriculture, and water-bodies will be impacted upon. Equally, absolute variability of annual rainfall is represented graphically against time in Figure 3, the period from 1984 to 1986 showed a rapid decrease in rainfall then went up in 1990 which was the highest absolute variability value recorded for the period. From 1990 to 2015 it had frequent fluctuation in between the period. Similarly, Fig. 4 show relative variability of annual rainfall. A noticeable phase can be seen in 2008 with a drop in annual rainfall. However, it exhibits a frequent ups and down within the study period. Although, relative variability experienced a downward trend $(-0.2015 \mathrm{~mm})$ but absolute variability showed a positive trend of $0.2899 \mathrm{~mm}$. From the result, one can say that Ebonyi State, being one of the State known for farming in Nigeria is experiencing increase in rainfall which is a great advantage for farming. Therefore, this advantage should be utilized for the benefit of the citizen for better prospect towards food security.

Table 1. Trends in rainfall totals for Ebonyi State

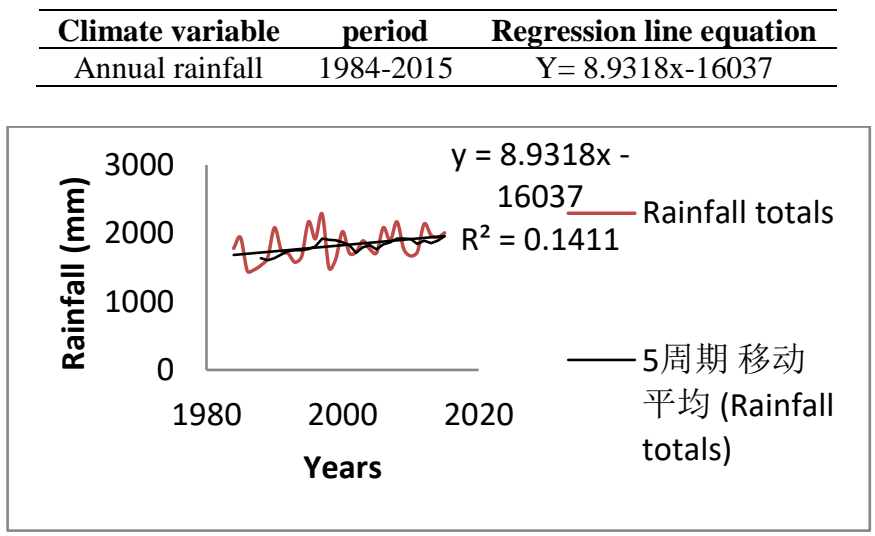

Figure 2. Trends of annual rainfall totals for Ebonyi state

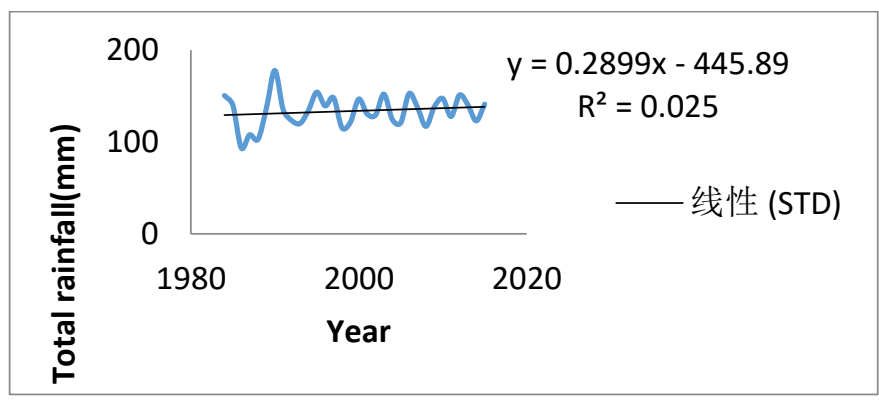

Figure 3. Standard deviation of annual rainfall totals

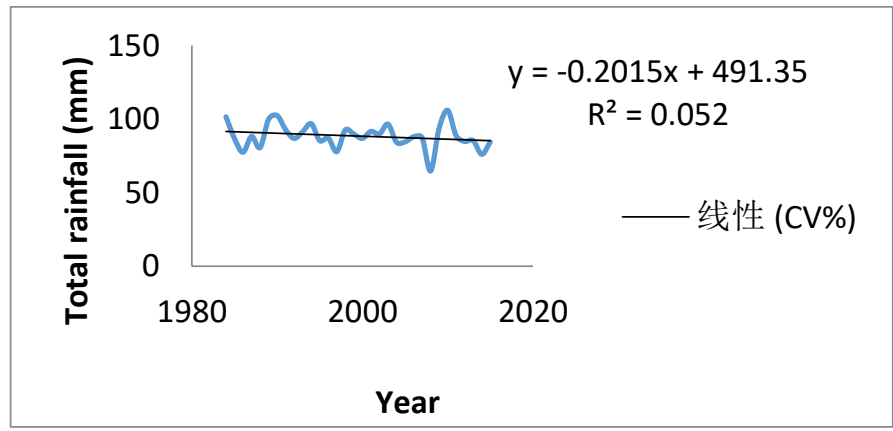

Figure 4. Coefficient of variation in annual rainfall totals 


\subsection{Decadal variability of rainfall}

In this study, three decades were considered in observing variability in rainfall over time. In Table 2 Total rainfall has increased over the decades. Average rainfall increased steadily over the decades also. But as for rainfall variability, rainfall volume in the area experienced slightly increasing trend. In the same manner, relative variability and absolute variability both increased during the first two decades but experienced a decline in the last two decades indicating variability.

Table 2. Decadal variability of rainfall over Ebonyi state from $1984-2015$

\begin{tabular}{cccccc}
\hline $\begin{array}{c}\text { climate } \\
\text { variable }\end{array}$ & $\begin{array}{c}\text { Statistical } \\
\text { tool }\end{array}$ & $\begin{array}{c}\mathbf{1 9 8 4}- \\
\mathbf{1 9 9 3}\end{array}$ & $\begin{array}{c}\mathbf{1 9 9 4}- \\
\mathbf{2 0 0 3}\end{array}$ & $\begin{array}{c}\mathbf{2 0 0 4}- \\
\mathbf{2 0 1 3}\end{array}$ & $\begin{array}{c}\mathbf{2 0 1 4}- \\
\mathbf{2 0 1 5}\end{array}$ \\
\hline Annual & Total & 16931 & 18512 & 18916 & 3951 \\
total & STD & 1288.08 & 1371.28 & 1357.16 & 264.25 \\
rainfall & CV \% & 907.35 & 894.11 & 866.94 & 160.38 \\
(mm) & Mean & 1693.08 & 1733.32 & 1891.49 & 1975.4 \\
\hline
\end{tabular}

\subsection{Hypothesis testing}

To test the hypothesis, the Total annual rainfall data from 1984- 2015 was computed in decades as shown in Table 3 and test statistics in Table 4. Kruskal-Wallis $\mathrm{H}$ test revealed that there was a statistically significant increase in rainfall between 1984 - 2015, at $\chi 2=6.325, \mathrm{p}=0.042<0.05$, with a mean rank pain score of 10.60 for first decade, 15.40 for second decade and 20.50 for third decade. Therefore, we can conclude that Ebonyi State experienced significant increase in rainfall from 1984 to 2015 . This increase could be attributed to the variability/change being experienced in climate over the study period.

Table 3. Decadal rainfall total from 1984- 2015

\begin{tabular}{cccc}
\hline \multicolumn{4}{c}{ Ranks } \\
\\
\hline \multirow{4}{*}{ Rainfall } & identifiers & $\mathrm{N}$ & Mean Rank \\
\cline { 2 - 4 } & first decade & 10 & 10.60 \\
\cline { 2 - 4 } & $\begin{array}{c}\text { second } \\
\text { decade }\end{array}$ & 10 & 15.40 \\
\cline { 2 - 4 } & third decade & 10 & 20.50 \\
\cline { 2 - 4 } & Total & 30 & \\
\hline
\end{tabular}

Table 4. Test statistics for Decadal rainfall total from 19842015

\begin{tabular}{cc}
\hline \multicolumn{2}{c}{ Test Statistics $^{\mathbf{a}, \mathbf{b}}$} \\
\hline \multicolumn{2}{c}{ Rainfall } \\
\hline Chi-Square & 6.325 \\
\hline $\mathrm{df}$ & 2 \\
\hline Asymp. Sig. & .042 \\
\hline \multicolumn{2}{c}{ a. Kruskal Wallis Test } \\
\hline b. Grouping Variable: identifiers \\
\hline
\end{tabular}

\section{CONCLUSIONS AND RECOMMENDATIONS}

This study examined trend and variability in rainfall over Ebonyi State, Nigeria between 1984 and 2015. The analysis showed that rainfall of the State has fluctuated substantially. The results revealed that there is a significant increase (positive trend) in rainfall of the study area, Therefore, from the results obtained from the study, the increasing rainfall in
Ebonyi State is a signal to the advantage that is derived from global warming in the area directly for crop farming and animal production indirectly which should be harness in order to boast food security and create employment in the State and Nigeria as a whole. It is important to state that, this increase in rainfall is an advantage for the study area and areas like it with this kind of setting where agriculture is the mainstay of the people and crop farming is greatly dependent on rain fed. But on the negative part is flooding, property destruction, pressures on dam walls, and so on which is occasioned by increased rainfall. Therefore proactive measures should be put in place by concern agency to reduce these adverse negative effects that comes with increasing rainfall which should include more dams to accommodate more water. Importantly, agriculture can be enhanced through this increasing rainfall towards job creation, food security and ultimately achieving agricultural sustainability.

\section{REFERENCES}

[1] Nwaobiala CU, Nwosu I. (2014). Effect of climate change on cassava farmers' output in Cross River State. Nigeria. I nt'l Journal of Agric. and Rural Development 17(1): 1628-1634.

[2] Chikezie C, Ibekwe UC, Ohajianya DO, Orebiyi JS, Henri-Ukoha A, Ukoha II, Osuji MN, Anthony, G. (2016). Climate change and perceived climate hazards: A trend analysis in Southeast Nigeria. International Journal of Weather, Climate Change and Conservation Research 2(1): 1-10.

[3] Osang JE1, Ewona IO, Obi EO, Udoimuk AB, Kamgba FA. (2013). Analyses of radiation and rainfall pattern In Kano State Northern Nigeria (1978-2007). International Journal of Scientific \& Engineering Research 4(9).

[4] Udoimuk AB, Osang JE, Ettah EB, Ushie PO, Egor AO, Alozie SI. (2014). An empirical study of seasonal rainfall effect In Calabar, Cross River State, Nigeria. Journal of Applied Physics (Iosr-Jap) E 5(5): 07-15.

[5] Hulme M, Osborn TJ, Johns TC. (1998). Precipitation sensitivity to global warming: Comparison of Observations with HADCM2 Simulations. Geophysical Re-Search Letters 25: 3379-3382.

[6] Kayano MT, Sansígolo C. (2008). Inter-annual to decadal variations of precipitation and daily maximum and daily minimum temperatures in Southern Brazil. Theoretical and Applied Climatology 97: 81-90. http//doi.org/ 10.1007/s00704-008-0050-4

[7] IPCC. (2007). Climate Change 2007: Impacts, Adaptation and Vulnerability: Contribution of Working Group II to the Fourth Assessment Report of the Intergovernmental Panel on Climate Change, Cambridge University Press, Cambridge, UK.

[8] Afangideh AI, Okpiliya FE, Eja EI. (2010). A Preliminary investigation into the annual rainfall trend and patterns for selected towns in Parts of South-Eastern Nigeria. Journal of Sustainable Development 3(3): 275282.

[9] National Oceanic and Administration, NOAA. (2008). Glossary of Coastal Terminology. New York: Coastal Services Centre Publication.

[10] Egor AOA, Osang JEA, Uquetan UIC, Emeruwa CB, Agbor MED. (2015). Inter annual variability of rainfall 
in some states of Southern Nigeria. International journal of Scientific \& Technology Research 4(10).

[11] Fidelis CO. (2015). Analysis of 30 years rainfall variability in Imo State of Southeastern, Nigeria. Hydrological Sciences and Water Security: Past, Present and Future (Proceedings of the 11th Kovacs Colloquium, Paris, France). IAHS Publ. 366.

[12] Nwaiwu IUO, Ohajianya DO, Orebiy JS, Ibekwe UC, Lemchi JI, Onyeagoch, SUO, Odoemena B, Utazi CO, Osuagwu CO, Tasie CM. (2014). Climate change trend and appropriate mitigation and adaptation strategies in Southeast Nigeria. G.J.B.A.H.S. 3(1): 120-125 (January - March, Famine Early Warning Systems Network (2017). Retrieved from http://www.fews.net/global/alert/January-25-2017. accessed 29/6/2017

[14] Zoellick Robert BA. (2009). Climate Smart future. The Nation Newspapers. Vintage press Limited, Lagos, Nigeria, 18.

[15] Ahmad AB, Mustapha BM. (2018). Monthly rainfall prediction using artificial neural network: A case study of Kano, Nigeria Environmental and Earth Sciences
Research Journal 5(2):

$37-41$.

https://doi.org/10.18280/eesrj.050201

[16] Onweremadu EU, Izuogu OP, Akamigbo FOR. (2011). Aggregation and a paedogenesis of seasonality inundated soil of the tropical watershed. Chiang Maij. Sci. 37(1): 74-84.

[17] Ogbuene EB. (2010). Impact of meteorological parameters on rice yield: An approach for environmental resource sustainability in Ebonyi rice farmland. Journal of environmental issues and agriculture in developing countries 2(2-3).

[18] Okoye BC, Onyenweaku CE, Ukoha OO. (2010). An ordered probit analysis of transaction cost and market participation by small - holder cassava farmers in Southeastern Nigeria. Nigeria Agricultural Journal 41(2).

[19] Sarker MAR. (2012). Impact of climate change on rice production and farmers' adaptation in Bangladesh. Ph.D. Thesis, University of Southern Queensland, Toowoomba, Australia.

[20] Waller DL. (2008). Statistics for Business, ButterworthHeinemann, Amsterdam. 